\title{
THE REDUCTION OF WAVE OVERTOPPING BY MEANS OF A STORM WALL
}

\author{
Koen Van Doorslaer ${ }^{1,2}$, Julien De Rouck ${ }^{1}$, Jentsje van der Meer ${ }^{3,4}$
}

A second edition of the EurOtop manual, a manual on wave overtopping of sea defenses and related structures, became available as pre-release in October 2016 on the website www.overtopping-manual.com. One of the improvements in this manual is based on the material in the current paper: how wave walls can reduce wave overtopping discharges. The base data set for the original advice in the previous EurOtop from 2007 is compared to the new developed procedures and new (unpublished) data collected in the wave flume of Ghent University. The comparative study shows that the differences are due to hydraulic differences in the test program. The original dataset from 1994 has tests with the still water level SWL both above and below the foot of the wall and was analyzed with an average slope analysis, where the UGent dataset only has tests with SWL below the foot of the wall and the small wall on top of the dike slope did not influence the average slope so that the actual slope could be used. The reduction factors deduced in analyzing the UGent datasets also work well for part of the original dataset, but not the other way around. The advice in the second edition of the EurOtop is thus to use the reduction factors by the UGent data analysis for wave walls above SWL, where the method proposed in the first edition can still be used for wave walls that have their foot below SWL. Both methodologies are explained in this paper.

Keywords: Wave overtopping; reduction factor; wave wall; breaking waves; non-breaking waves; storm wall

\section{INTRODUCTION}

EurOtop (2007) briefly discusses the 'effect of wave walls' on wave overtopping over coastal dikes, in its section 5.3.5. It states that relatively small vertical walls placed on top of a slope can have a significant influence on the reduction of wave overtopping. It is also stated that the knowledge is quite limited and only a few model studies were available, within a well specified range of application. Based on this information, a reduction factor $\gamma_{\mathrm{v}}$ is proposed to be introduced in the formula for breaking waves only. No reduction factor is available in the formula for non-breaking waves. To distinguish between breaking and non-breaking waves, the average slope was used with the wave wall replaced by a virtual 1:1 slope.

For steep dike slopes with small wave walls on top, the presence of such a wave wall hardly influences the average slope. The absence of a $\gamma_{\mathrm{v}}$ coefficient in the non-breaking wave formula formed the starting point of an intensive research campaign carried out at Ghent University, where many reductive measures on top of steep dike slopes have been investigated. Results, only for non-breaking waves, have been published in Van Doorslaer et al. (2015). That research shows the necessity of a reduction factor $\gamma_{v}$ for wave walls for non-breaking waves.

In this paper, it is investigated by a thorough study of both datasets why two different datasets give two different results. Why does EurOtop (2007) does not use $\gamma_{\mathrm{v}}$ in the formula for non-breaking waves, where Van Doorslaer et al. (2015) do use this factor? To have a full coverage of both breaking and nonbreaking waves, also new tests at Ghent University have been done for breaking waves.

First, a section is devoted to the present formulae to calculate wave overtopping. Subsequently, the paper focuses on the dataset used for EurOtop (2007) and the datasets from Ghent University, both the non-breaking data from Van Doorslaer et al. (2015) and the breaking data in a new dataset. Next, the analysis of the individual datasets is given, before a comparison between the different methodologies is made in a next section. The paper is concluded by a clear advice on how to include the effect of wave walls in the existing overtopping formulae.

\section{OVERTOPPING FORMULAE}

\section{EurOtop (2016) versus EurOtop (2007)}

The average overtopping discharge over a sloping structure (dike, levee, breakwater...) is given in EurOtop (2007), based on van der Meer and Janssen (1994), by following formulae:

$$
\frac{q}{\sqrt{g \cdot H_{m 0}^{3}}}=\frac{0.067}{\sqrt{\operatorname{tan\alpha }}} \cdot \gamma_{b} \cdot \xi_{m-1,0} \cdot \exp \left(-4.75 \cdot \frac{R_{C}}{H_{m 0}} \cdot \frac{1}{\xi_{m-1,0} \cdot \gamma_{b} \cdot \gamma_{f} \cdot \gamma_{\beta} \cdot \gamma_{v}}\right)
$$

\footnotetext{
${ }^{1}$ Dept. Of Civil Engineering, Ghent University, Technologiepark 904, 9052 Zwijnaarde, Belgium. +3292645489 koenvandoorslaer@gmail.com,j.derouck@hotmail.com

2 Dredging, Environmental and Marine Engineering (DEME), Scheldedijk 30, 2070 Zwijndrecht, Belgium.

${ }^{3}$ Van der Meer Consulting bv, P.O. Box 11, Akkrum, 8490 AA, The Netherlands, jm@vandermeerconsulting.nl

${ }^{4}$ UNESCO IHE, Westvest 7, Delft, 2611 AX, The Netherlands, j.vandermeer@unesco-ihe.org
} 


$$
\text { with a maximum of: } \frac{q}{\sqrt{g \cdot H_{m 0}^{3}}}=0.2 \cdot \exp \left(-2.6 \cdot \frac{R_{C}}{H_{m 0}} \cdot \frac{1}{\gamma_{f} \cdot \gamma_{\beta}}\right)
$$

where $\mathrm{q}\left(\mathrm{m}^{3} / \mathrm{m} / \mathrm{s}\right)$ is the average overtopping discharge, $\mathrm{g}$ the gravity acceleration $\left(9.81 \mathrm{~m} / \mathrm{s}^{2}\right), \mathrm{H}_{\mathrm{m} 0}$ the spectral wave height at the toe of the structure, $\alpha$ the slope of the structure, $\xi_{\mathrm{m}-1,0}$ the wave breaker parameter based on the spectral wave period $T_{m-1,0}, R_{c}$ the crest freeboard and $\gamma$ a reduction factor for the influence of a berm $\left(\gamma_{\mathrm{b}}\right)$, roughness of the slope $\left(\gamma_{\mathrm{f}}\right)$, a vertical wall on top of the slope $\left(\gamma_{\mathrm{v}}\right)$ or wave obliqueness $\left(\gamma_{\beta}\right)$.

Eq. [1] (breaking waves) is used until a maximum is reached in Eq. [2] (non-breaking waves). In a log-linear graph, these equations give a straight line.

When a certain influence is not present, the reduction factor $\gamma$ is set equal to 1 . A value lower than 1 indicates a reduction of the overtopping discharge, shown by a virtual increase of the crest freeboard. As already mentioned in Chapter 1, only for breaking waves (Eq. [1]) a reduction for wave walls is included whereas $\gamma_{\mathrm{v}}$ is not included in Eq. [2]

Van der Meer and Bruce (2014), based on data made available by Victor (2012), a revision of early Dutch work from the 1970s and other datasets from the CLASH database, have modified the equations [1] and [2] to the following set of equations:

$$
\begin{aligned}
& \frac{q}{\sqrt{g \cdot H_{m 0}^{3}}}=\frac{0.023}{\sqrt{\tan \alpha}} \cdot \gamma_{b} \cdot \xi_{m-1,0} \cdot \exp \left[-\left(2.7 \cdot \frac{R_{C}}{H_{m 0}} \cdot \frac{1}{\xi_{m-1,0} \cdot \gamma_{b} \cdot \gamma_{f} \cdot \gamma_{\beta} \cdot \gamma_{v}}\right)^{1.3}\right] \\
& \text { with a maximum of: } \frac{q}{\sqrt{g \cdot H_{m 0}^{3}}}=0.09 \cdot \exp \left[-\left(1.5 \cdot \frac{R_{C}}{H_{m 0}} \cdot \frac{1}{\gamma_{f} \cdot \gamma_{\beta}}\right)^{1.3}\right]
\end{aligned}
$$

These equations are also included in EurOtop (2016), with only one difference: the influence of a wave wall is included in the exponential part of the formula for non-breaking waves, based on the results of the present work which will be explained later in this paper. The equations given in EurOtop (2016) are the following:

$$
\begin{gathered}
\frac{q}{\sqrt{g \cdot H_{m 0}^{3}}}=\frac{0.023}{\sqrt{\tan \alpha}} \cdot \gamma_{b} \cdot \xi_{m-1,0} \cdot \exp \left[-\left(2.7 \cdot \frac{R_{C}}{H_{m 0}} \cdot \frac{1}{\xi_{m-1,0} \cdot \gamma_{b} \cdot \gamma_{f} \cdot \gamma_{\beta} \cdot \gamma_{v}}\right)^{1.3}\right] \\
\text { with a maximum of: } \frac{q}{\sqrt{g \cdot H_{m 0}^{3}}}=0.09 \cdot \exp \left[-\left(1.5 \cdot \frac{R_{C}}{H_{m 0}} \cdot \frac{1}{\gamma_{f} \cdot \gamma_{\beta} \cdot \gamma_{v}}\right)^{1.3}\right]
\end{gathered}
$$

Due to the exponent 1.3, eq. [3], [4] and [5] no longer give a straight line in the log-linear graph but give a slight curved trend. For sloping structures with freeboard $\mathrm{R}_{\mathrm{c}} / \mathrm{H}_{\mathrm{m} 0}>0.5$ the difference between these new formulae and the ones from EurOtop (2007) is small. The improvement of eq. [3] to [5] is mainly in the area for very low freeboards, including zero freeboard: $0 \leq \mathrm{R}_{\mathrm{c}} / \mathrm{H}_{\mathrm{m} 0} \leq 0.5$. The previous equations [1] and [2] were only valid for $\mathrm{R}_{\mathrm{c}} / \mathrm{H}_{\mathrm{m} 0}>0.5$ but were maybe (mis)used for smaller freeboards too. It can be seen in Figure 1 (for non-breaking waves) that in this zone of small freeboards the largest differences occur. Almost identical conclusions can be seen in Figure 2 for breaking waves. In EurOtop (2016) the absolute numbers of the difference between old EurOtop (2007) and new EurOtop (2016) formulae are given: $+/-30 \%$. It is concluded that this difference is much smaller than the reliability of overtopping predictions which shows to be a factor 2.5 (for the largest overtopping discharges) to 20 (for the smallest overtopping discharges) based on the $90 \%$ confidence interval of the measured data. 


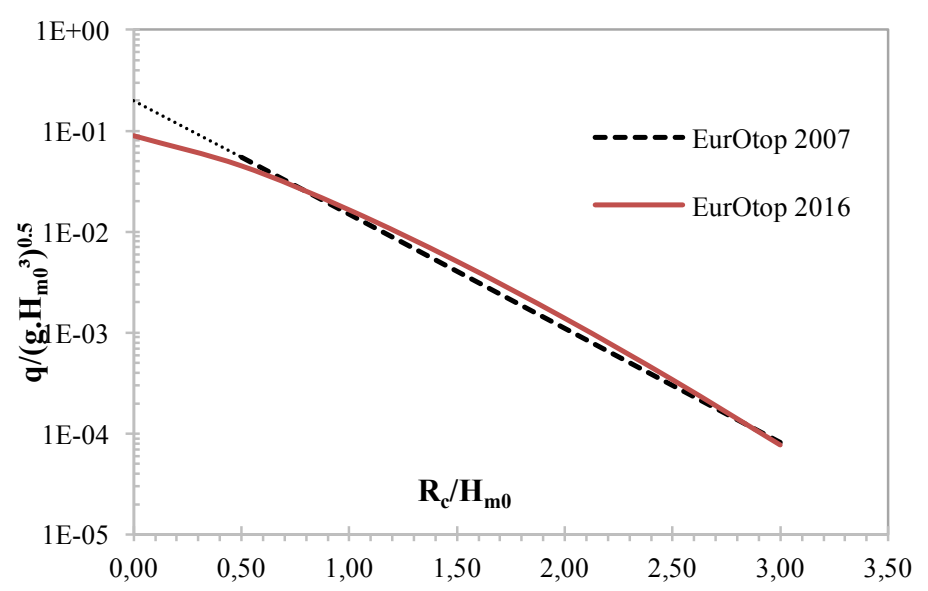

Figure 1. Comparison of EurOtop (2007) formula for non-breaking waves with the new formula in EurOtop (2016).

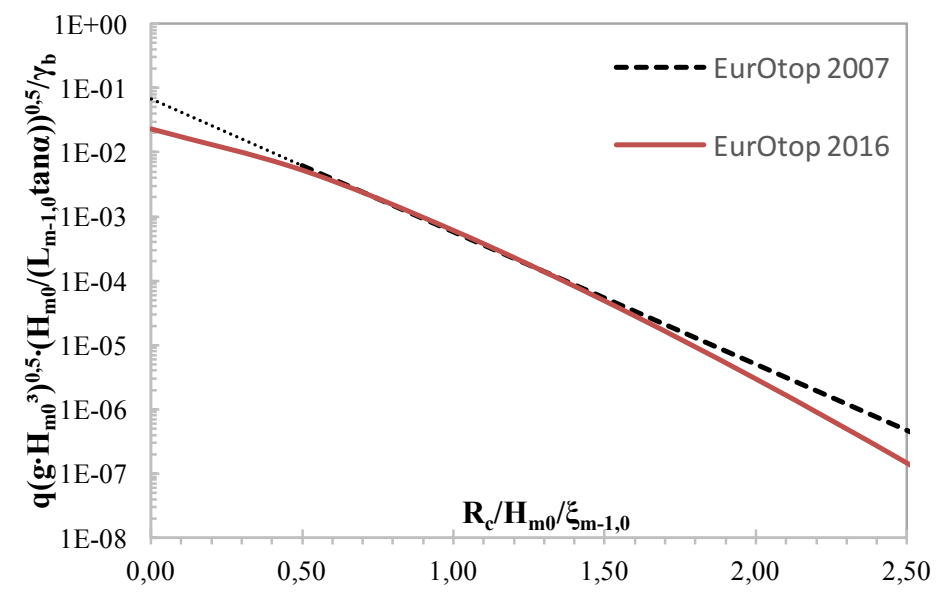

Figure 2. Comparison of EurOtop (2007) formula for breaking waves with the new formula in EurOtop (2016)

\section{Reduction factors}

The reduction factors $\gamma$ in EurOtop (2007), Van Doorslaer et al. (2015) and other research have been derived with the former formulae [1] and [2]. They can be found in the exponential part of the formula, see Eq. [6]:

$$
\frac{q}{\sqrt{g \cdot H_{m 0}^{3}}}=a \cdot \exp \left(-b \cdot \frac{R_{C}}{H_{m 0} \cdot \gamma}\right)
$$

Since the formula has been changed to the shape of Eq. [7] the reduction factor $\gamma$ also has the exponent 1.3 .

$$
\frac{q}{\sqrt{g \cdot H_{m 0}^{3}}}=a \cdot \exp \left[-b \cdot\left(\frac{R_{C}}{H_{m 0} \cdot \gamma}\right)^{1.3}\right]
$$

Although mathematically different equations, the same reduction factors as derived for Eq. [6] can still be used in Eq. [7]. Reduction factors are always derived as the difference between a structure with and a structure without influence element (roughness, berm, vertical wall, obliqueness or other influences). It's by definition a relative value showing the amount of reduction. Regardless whether $\gamma$ was derived for the former formula Eq. [6] or the new formula Eq. [7], as long as both the reference situation (without reducing element) and the reducing geometry (with reducing element) have been defined by the same type of equation, the outcome $\gamma$ can be used in any other overtopping equation: the relative reduction factor $\gamma$ remains unchanged and can be included in the new formula.

An example case is given in Table 1 to prove the above statement: overtopping is calculated over a steep smooth sloping structure, non-breaking waves (eq. [2] resp. [5]). The freeboard $\mathrm{R}_{\mathrm{c}}$ is $2 \mathrm{~m}$, the wave height $\mathrm{H}_{\mathrm{m} 0}=1.5 \mathrm{~m}$. 


\begin{tabular}{|l|l|c|c|}
\hline \multicolumn{4}{|l|}{$\begin{array}{l}\text { Table 1. Example case: absolute values of old formula versus new formula change, but the } \\
\text { amount of reduction remains the same regardless of which formula is used. }\end{array}$} \\
\hline q for $\mathbf{R}_{\mathrm{c}}=\mathbf{2 m}, \mathbf{H}_{\mathrm{m} \mathbf{0}}=\mathbf{1 . 5 m}$ & Former formula (Eq. [2]) & New formula (Eq. [5]) & $\%$ difference \\
\hline No reduction factor & $35.9 \mathrm{l} / \mathrm{m} / \mathrm{s}$ & $44.1 \mathrm{l} / \mathrm{m} / \mathrm{s}$ & $18.6 \%$ \\
\hline Including $\gamma=\mathbf{0 . 7}$ & $8.1 \mathrm{l} / \mathrm{m} / \mathrm{s}$ & $10.3 \mathrm{l} / \mathrm{m} / \mathrm{s}$ & $21.4 \%$ \\
\hline$\%$ reduction & $77.4 \%$ & $76.6 \%$ & $0.8 \%$ \\
\hline
\end{tabular}

The absolute values for both the reference situation and the situation with reduction element are different when using the EurOtop (2016) formula (Eq. [5]) compared to the former formula (Eq. [2]): 18.6 resp. $21.4 \%$ more overtopping when using the new formulae (larger overtopping can also be seen on Figure 2 for $\mathrm{R}_{\mathrm{c}} / \mathrm{H}_{\mathrm{m} 0}=1.33$ ). But the relative value hardly changes at all: the same ratio of discharge with/without measure is obtained regardless which formula is used: both formulae are reduced with about $77 \%$. A similar conclusion can be found for breaking waves Eq. [1] vs Eq. [3].

It can be concluded, which has also been done in EurOtop (2016) Figure 5.16, that the reduction factors as derived in the past can be used in the new overtopping formulae [3] and [5].

\section{HARLINGEN DATASET (1994)}

The "Harlingen dataset", named after its location in the North of the Netherlands, was the result of a request by the Dutch government (Rijkswaterstaat) to study modifications to the coastal defense system in Harlingen, but also to develop general design formulae for wave run-up and overtopping for wave walls on top of a structure. A series of tests has been carried out in 1994 in Delft Hydraulics' (currently named Deltares) wave flume 'Scheldegoot', partly tests with a quay and partly tests with a dike. The background of these tests is given in report H2014 by Den Heijer (1998), the analysis of the tests with dike is redone in report H2458 by Van der Meer (1997). The Harlingen dataset was part of a wider test program on wave run-up and overtopping at dikes, which formed the base of the TAW (2002) manual.

The 'Scheldegoot' is a wave flume of $55 \mathrm{~m}$ long, $1 \mathrm{~m}$ wide and $1.2 \mathrm{~m}$ deep. Irregular waves with a JONSWAP spectrum were generated and the wave paddle was equipped with active wave absorption. In total 3 sets of wave gauges were installed along the flume: one set near the wave paddle for the active absorption, one set $5 \mathrm{~m}$ in front of the dike and one set near the toe of the dike. Sampling frequency of the measuring instruments was $50 \mathrm{~Hz}$.

In total 38 tests of the Harlingen dataset, the ones with a dike, are of interest for the present scope. They can be found in the CLASH database, series 223. Series 223 can be split up in 3 different geometries:

- $\quad$ Smooth slope $\cot (\alpha)=2.5$ with wave wall, see Figure 3 (4 tests)

- $\quad$ Smooth slope $\cot (\alpha)=3.0$ with wave wall, see Figure 3 (16 tests)

- Smooth slope $\cot (\alpha)=3.0$ with a small horizontal berm in front of the wall of $0.40 \mathrm{~m}$ at crest level, see Figure 4 (18 tests)

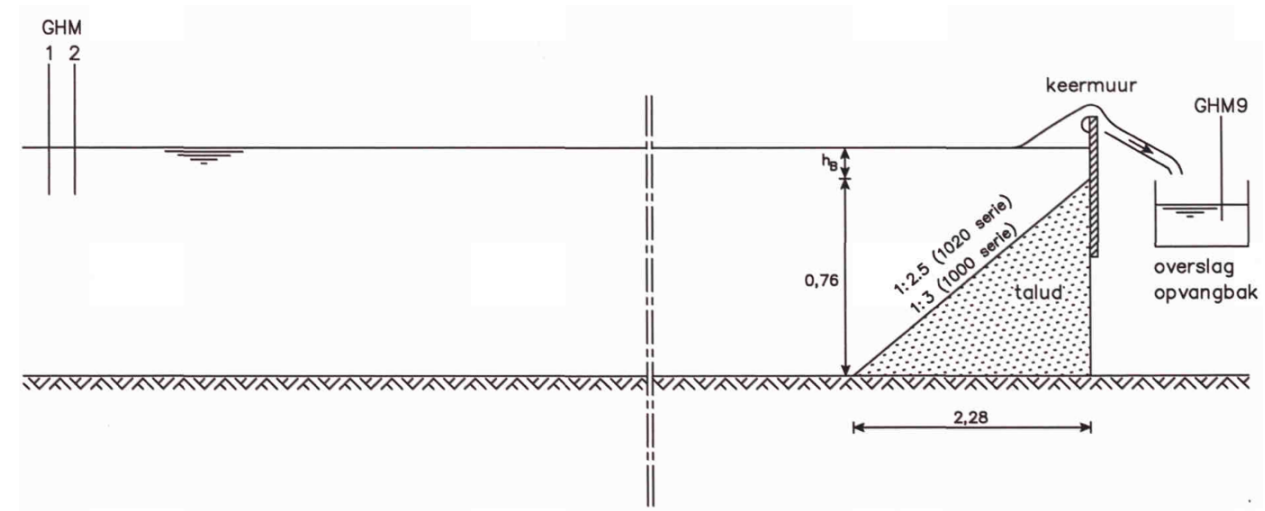

Figure 3. Smooth dike slope $(\cot (\alpha)=2.5$ or 3$)$ with vertical wall. Figure by Den Heijer (1998) 


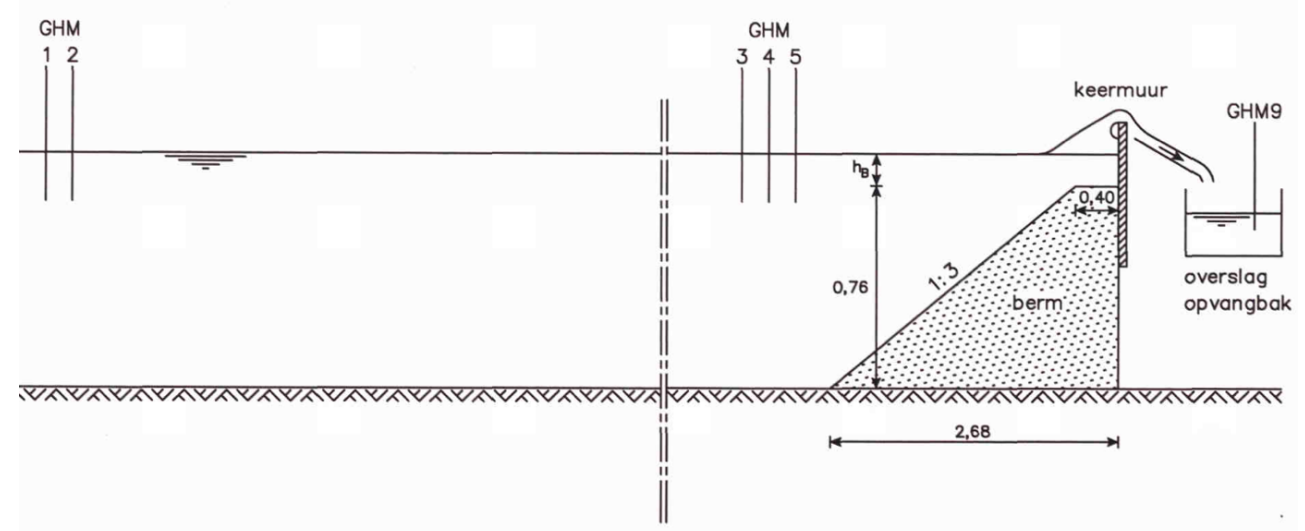

Figure 4. Smooth dike slope $(\cot (\alpha)=3)$ with berm at crest level $(0.4 \mathrm{~m}$ long) and vertical wall. Figure by Den Heijer (1998)

The Harlingen dataset was carried out within the following range of parameters:

- Dimensionless freeboard $1.5 \leq \mathrm{R}_{\mathrm{c}} / \mathrm{H}_{\mathrm{m} 0} \leq 3.0$

- The foot of the wall was between 1.2 times the wave height above the still water level SWL (emerged wall) and 1.2 times the wave height below SWL (submerged wall).

- The relative length of the berm, $\mathrm{B} / \mathrm{L}_{0 \mathrm{p}}$, was between 0.05 and 0.08 . The ratio $\mathrm{B} / \mathrm{H}_{\mathrm{m} 0}$ was between 2 - 3 .

- The minimal height of the wall was about 0.5 times $\mathrm{H}_{\mathrm{m} 0}$, the maximal height was about 3 times $\mathrm{H}_{\mathrm{m} 0}$.

- $\quad$ The wave steepness with the peak period $\mathrm{s}_{\mathrm{op}}$ was between 0.02 and 0.04 .

\section{THE UGENT DATASETS}

In the framework of the Coastal Safety Plan (Mertens et al. (2008)) by the Flemish Government, many tests were carried out in the wave flume of Ghent University to study the reduction of wave overtopping. Most of these tests were performed with a Belgian type geometry when the beach nourishments were not yet in place. This means, a smooth dike slope $(\cot (\alpha)=2$ and 3$)$ with a high water level in front of the dike. This combination led to non-breaking waves. The tests were carried out in a midsize wave flume of Ghent University: $30 \mathrm{~m}$ length, $1 \mathrm{~m}$ width, $1.2 \mathrm{~m}$ height, with a working water depth of $0.8 \mathrm{~m}$ (see Figure 5). The results of these studies have been published in Van Doorslaer et al. (2015).

Besides the tests with steep dikes (non-breaking waves), also tests on a mild dike slope have been carried out. They were done in the small wave flume of Ghent University: $15 \mathrm{~m}$ length, $0.35 \mathrm{~m}$ width, $0.60 \mathrm{~m}$ height. A smooth dike with slope 1:6 was used for the tests. Similar to the non-breaking wave tests described above, also deep water in front of the structure was tested. However, due to the mild sloping dike, the breaker parameter $\xi_{\mathrm{m} 0}$ was much lower and the test results were always in the zone of breaking waves. The outcome of the analysis has been published in EurOtop (2016), but the background and analysis itself is given in the present paper.

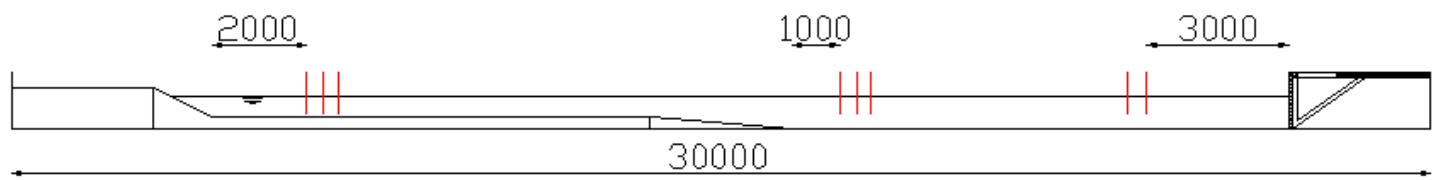

Figure 5. Midsize wave flume at the Coastal Engineering Dept. of Ghent University, equipped with 3 sets of wave gauges. The flume is double the size in length of the small scale wave flume. Figure by Van Doorslaer et al. (2015)

Both UGent flumes are equipped with a piston type wave paddle and have active wave absorption. In total 3 sets of wave gauges ( 2 gauges in front of the wave paddle, 3 at a deeper section in the flume, 3 near the toe of the structure) were installed to measure the wave conditions and separate the incoming waves from the reflecting waves near the toe of the structure. Spectral waves have been used with a JONSWAP 3.3 spectrum. Unlike the Harlingen dataset, the most important difference for the UGent datasets is that the foot of the wall was always located above the still water level. 
To find the influence of a particular item on overtopping, a wave wall in this case, it is always important to have a good reference situation. Therefore, 80 tests have been carried out in UGent's midsize flume and 19 in UGent small size flume on a smooth dike slope without wave wall present, serving as a reference dike. This way of working was preferred over using formulae from literature: the test set-up, measuring devices and -techniques are then the same for the reference case as well as for dike with wave wall, which guarantees good comparison and excludes model effects.

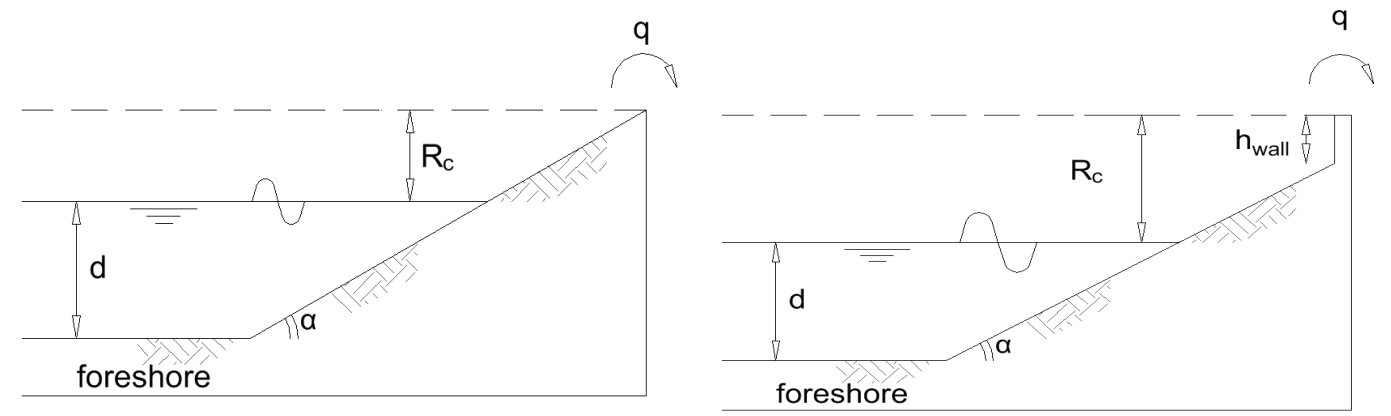

Figure 6. Smooth dike slope (reference situation) in the left, smooth dike slope with storm wall in the right. Figures by Van Doorslaer et al. (2015)

The parameter range used for the UGent datasets is given in Table 2. The dike slope was smooth $\left(\gamma_{\mathrm{f}}=1\right)$, perpendicular waves $\left(\gamma_{\beta}=1\right)$ were tested and no berms were present in the dike slope $\left(\gamma_{\mathrm{b}}=1\right)$.

\begin{tabular}{|c|c|c|c|}
\hline \multicolumn{2}{|c|}{ Dataset 1: mid size wave flume, non-breaking waves } & \multirow{6}{*}{$\begin{array}{c}\text { Reference dike } \\
2 \text { and } 3 \\
2.10-4.90 \\
0.83-3.15 \\
\text { no wall } \\
80\end{array}$} & \multirow{6}{*}{$\begin{array}{c}\text { Dike with wave wall } \\
2 \text { and } 3 \\
2.20-4.80 \\
0.60-2.60 \\
0.08-1.60 \\
117\end{array}$} \\
\hline Slope angle of the smooth dike slope & $\cot (\alpha)$ & & \\
\hline Wave breaker parameter with actual slope & $\xi_{\mathrm{m}-1,0}$ & & \\
\hline Dimensionless freeboard & $\mathrm{R}_{\mathrm{c}} / \mathrm{H}_{\mathrm{m} 0}$ & & \\
\hline Dimensionless wall height & $h_{\text {wall }} / R_{c}$ & & \\
\hline Number of tests & & & \\
\hline \multicolumn{2}{|c|}{ Dataset 2: small size wave flume, breaking waves } & Reference dike & Dike with wave wall \\
\hline Slope angle of the smooth dike slope & $\cot (\alpha)$ & 6 & 6 \\
\hline Wave breaker parameter with actual slope & $\xi_{\mathrm{m}-1,0}$ & $0.80-1.01$ & $0.77-0.96$ \\
\hline Dimensionless freeboard & $\mathrm{R}_{\mathrm{c}} / \mathrm{H}_{\mathrm{m} 0}$ & $0.56-1.50$ & $0.46-1.61$ \\
\hline Dimensionless wall height & $\mathrm{h}_{\mathrm{wall}} / \mathrm{R}_{\mathrm{c}}$ & no wall & $0.08-0.60$ \\
\hline Number of tests & & 19 & 31 \\
\hline
\end{tabular}

\section{ANALYSIS}

\section{The Harlingen dataset}

When the data on the three different geometries with wave wall are plotted in a log-linear diagram in Figure 7, they show to be below EurOtop (2007)'s reference line for non-breaking waves. It is investigated in Van der Meer (1997) if, by introduction of an influence factor for the wave wall, the existing formulae can better predict the data. 


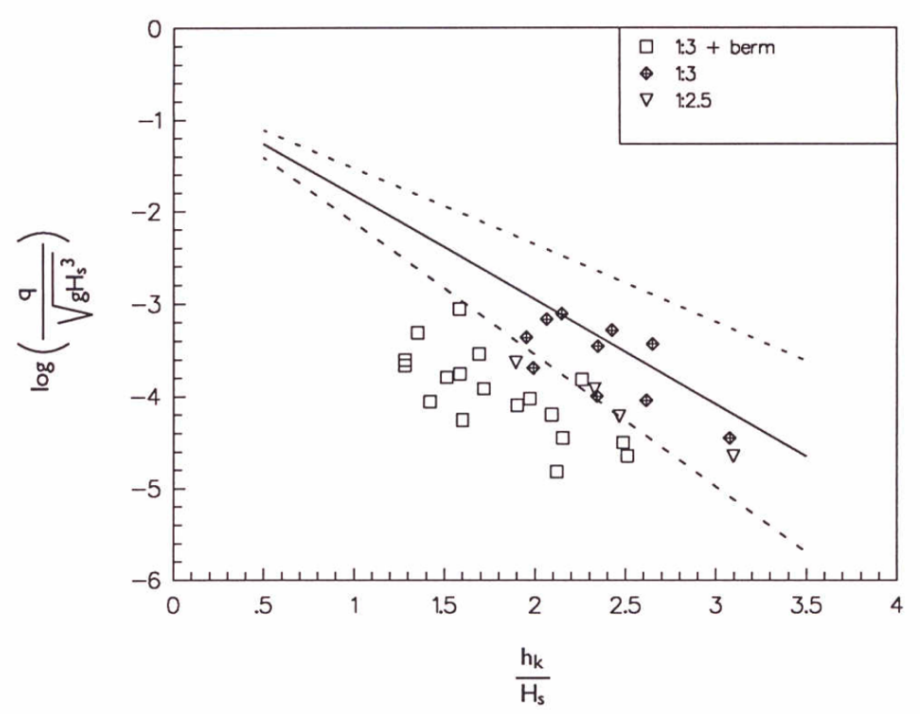

Figure 7. All tests in the Harlingen dataset (slope 1:2.5 with wave wall, slope 1:3 with wave wall and slope 1:3 with promenade and wave wall) plotted in the non-breaking overtopping graph are below EurOtop (2007) line Eq. [2]. Figure by Van der Meer (1997).

Van der Meer and Janssen (1994), TAW (2002) and EurOtop (2007), all based on this (and other) datasets, work with the average slope to calculate the wave breaker parameter which defines whether to use the formula for breaking or non-breaking waves. The average slope is calculated between 1.5 times the wave height below the still water level and the run-up height above still water level, as shown in Figure 8 .

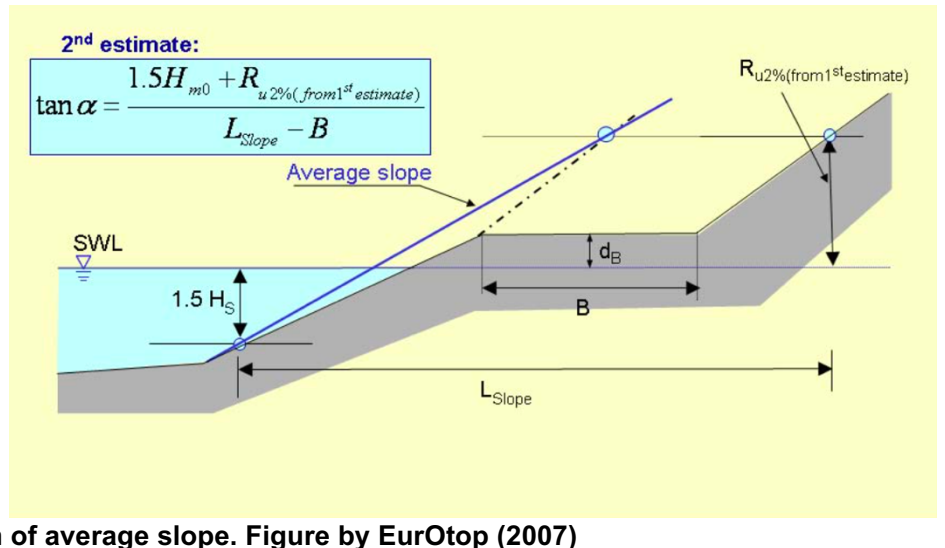

Figure 8. Definition of average slope. Figure by EurOtop (2007)

In the Harlingen dataset, the (sometimes large) wave wall on top leads to steep average slopes and high breaker parameters by the above procedure. As a consequence, the waves are classified as nonbreaking, regardless the fact that the wave wall might have a high location and almost no influence on the breaking of the waves on the dike slope. Therefore, the report H2458 investigates the replacement of the vertical wall by a certain slope to calculate the average slope and consequently wave breaker parameter for better representation of the data.

Best results are found to replace the vertical wall by a 1:1 slope to calculate the average slope, and also to change the boundary between breaking and non-breaking from $\gamma_{b} \xi_{0 p}=2$ to $\gamma_{b} \xi_{0 p}=3$. By doing so, quite some data points have moved from the non-breaking regime to the breaking regime, see Figure 9. The ones in the non-breaking graph (Figure 9, left) are presented well and don't need any further improvement. The ones shifted to the breaking graph (Figure 9, right) are below the confidence interval but are well grouped so that a trendline can be drawn through the middle of the data group and a reduction factor can be extracted to be included in the graph. Note that for the breaking waves (Figure 9 , right) an influence factor for the berm $\gamma_{b}$ already is included where required. 

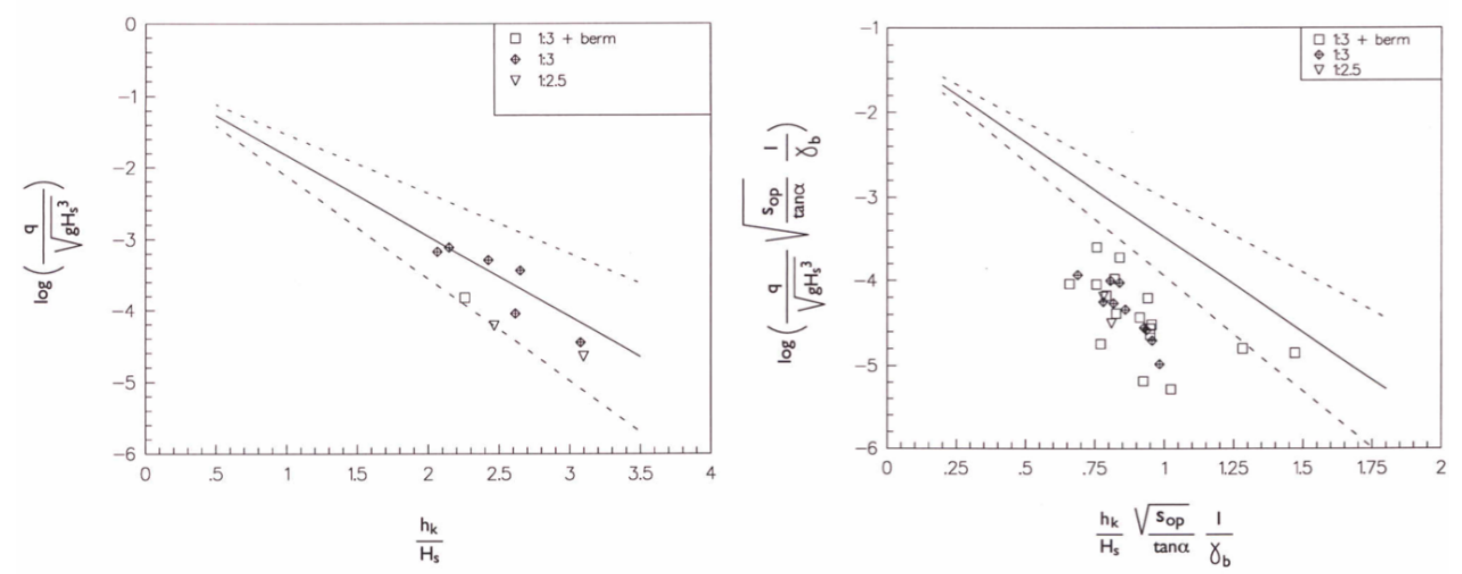

Figure 9. Harlingen dataset with equivalent slope calculation by changing the vertical wall into a 1:1 slope. The boundary between the non-breaking waves (left) and breaking waves (right) is set at $\gamma_{b} \xi_{0 p}=3$. Figures by van der Meer (1997)

The trendline analysis in Figure 9 right led to a reduction factor $\gamma_{\mathrm{v}}=0.65$. When including this in the denominator of the horizontal axis (increasing the virtual freeboard), the data points are presented better by the formula for breaking waves, see Figure 10 .

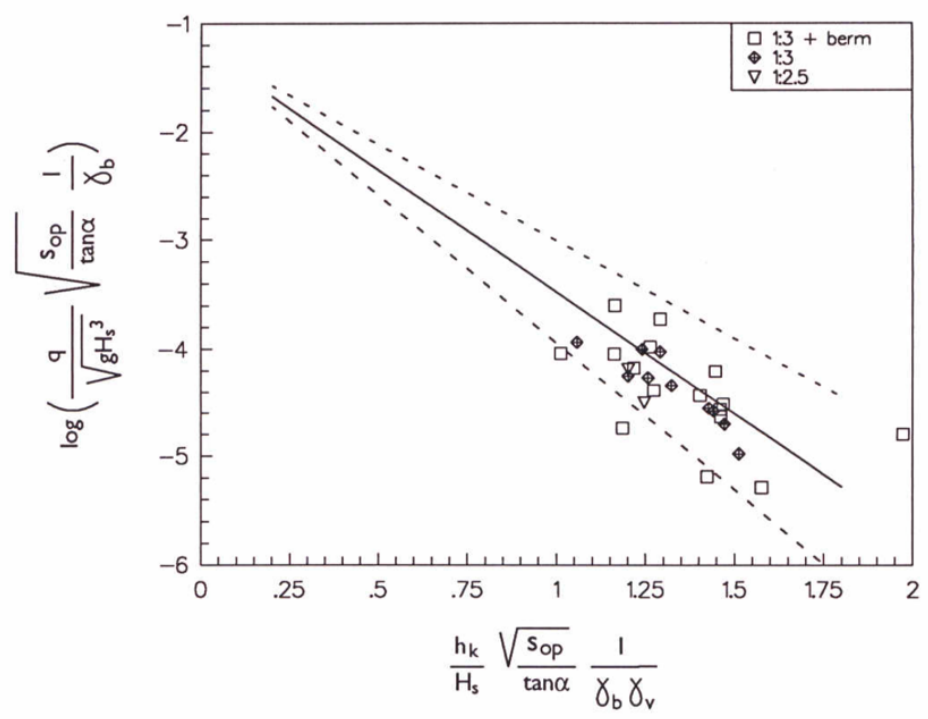

Figure 10. Breaking waves of the Harlingen dataset by replacing the vertical wall into a 1:1 slope, by setting the boundary of breaking waves at $\gamma_{b} \xi_{0 p} \leq 3$ instead of 2 , and by introducing a reduction factor $\gamma_{v}=0.65$ on the horizontal axis. Figure by van der Meer (1997).

The Harlingen data are now represented well in Figure 9 left (non-breaking waves, $\gamma_{b} \xi_{0 p} \geq 3$ ) and in Figure 10 (breaking waves, $\gamma_{b} \xi_{0 \mathrm{p}} \leq 3$ ) after changing the vertical wall into a 1:1 slope to calculate the average slope.

This section has given an explanation why the reduction factor $\gamma_{\mathrm{v}}$ for wave walls only is present in the formula for breaking waves Eq. [1] and not in the formula for non-breaking waves Eq. [2].

\section{UGent dataset for non-breaking waves}

In Van Doorslaer et al. (2015), the analysis and results have been presented based on the EurOtop (2007) equations. The achieved reduction factor $\gamma$ can be used in the new EurOtop (2016) formulae with the same accuracy in terms of reduction of wave overtopping. In contrast with the previous section, in this section the actual slope $\alpha$ is used for calculating the breaker parameter. Since the wave wall on top of the dike slope used in the UGent tested geometries is relatively small, the wave breaker parameter is almost the same whether the actual slope $\left(\alpha_{\text {actual }}\right.$ in Figure 11) or the average slope $\left(\alpha_{\text {avg }}\right.$ in Figure 11) is used; waves remain non-breaking. To keep it simple, it was decided to continue working with the actual slope. 


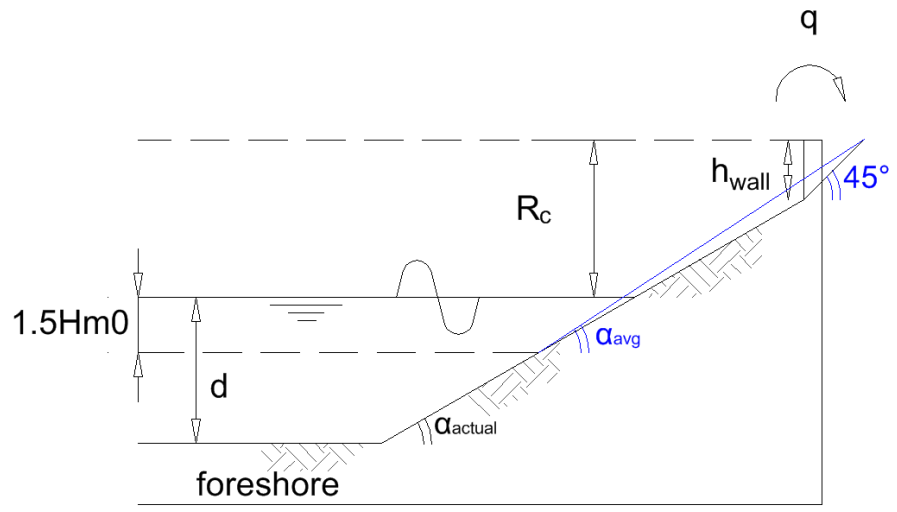

Figure 11. The actual slope and the average slope are almost identical for geometries where the slope is dominant over the storm wall. In such situations, for simplicity, the actual slope is used to determine the breaker parameter.

The test results of the reference case (Figure 6, left) are plotted in a log-linear diagram: see Figure 12. An exponential trendline is fitted through the data and gives the reference formula to calculate the average overtopping discharge on a smooth dike slope under non-breaking wave conditions: Eq. [8].

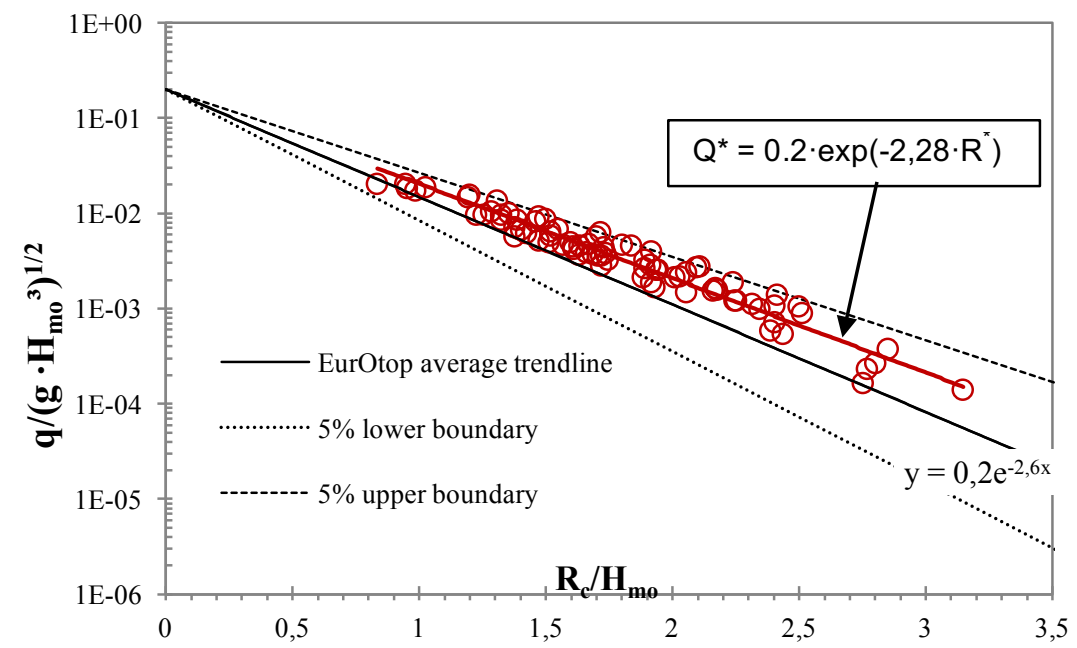

Figure 12. Results of the reference situation (a smooth dike slope without wave wall) for non-breaking waves. Figure by Van Doorslaer et al. (2015)

$$
\frac{q}{\sqrt{g \cdot H_{m 0}^{3}}}=0.2 \cdot \exp \left(-2.28 \cdot \frac{R_{c}}{H_{m 0}}\right)
$$

It can be noticed that the scatter around this trend line is small. When taking the exponential coefficient as normally distributed stochastic variable, the mean value is 2.28 with a standard deviation of 0.15. It's also clear that the results are located above the average trend line in EurOtop 2007 (formula [2]) resulting in a slightly higher exponential coefficient: 2.28 instead of 2.6. In Van Doorslaer et al. (2015) is shown that if a selection is made in the CLASH dataset with similar boundary conditions $\left(\beta=0^{\circ}, \gamma_{\mathrm{f}}=1, \mathrm{R}_{\mathrm{c}}>0, \ldots\right)$ the same conclusion can be drawn for 255 other tests. However, the value 2.28 will only be used in this paper as a reference case to which the tests with storm wall will be related, and not to replace EurOtop (2007)'s Eq. [2].

If a wave wall is present on top of the dike slope (Figure 6, right), the overtopping discharges measured are lower than on a dike without wave wall and the same freeboard $\mathrm{R}_{\mathrm{c}}$. This can be seen in Figure 13: for a constant dimensionless freeboard, the data points with wave wall are below the red trendline from the reference situation. They tend to much steeper slopes and vertical structures (dashed lines in Figure 13). Even more, the height of the wave wall also has an influence. When looking at fixed dimensionless freeboard $\mathrm{R}_{\mathrm{c}} / \mathrm{H}_{\mathrm{m} 0}$ (vertical line in Figure 13), the data for storm wall $8 \mathrm{~cm}$ (cross) is lower than wall $6 \mathrm{~cm}$ (square), $4 \mathrm{~cm}$ (circle) and $2 \mathrm{~cm}$ (diamond): the higher the wall, for a constant 
dimensionless freeboard, the lower the overtopping discharge. It is, unlike the conclusion in the previous section, clear that an influence factor should be introduced in Eq. [8] for non-breaking waves. The equation turns into Eq. [9]:

$$
\frac{q}{\sqrt{g \cdot H_{m 0}^{3}}}=0.2 \cdot \exp \left(-2.28 \cdot \frac{R_{c}}{H_{m 0}} \cdot \frac{1}{\gamma_{v}}\right)
$$

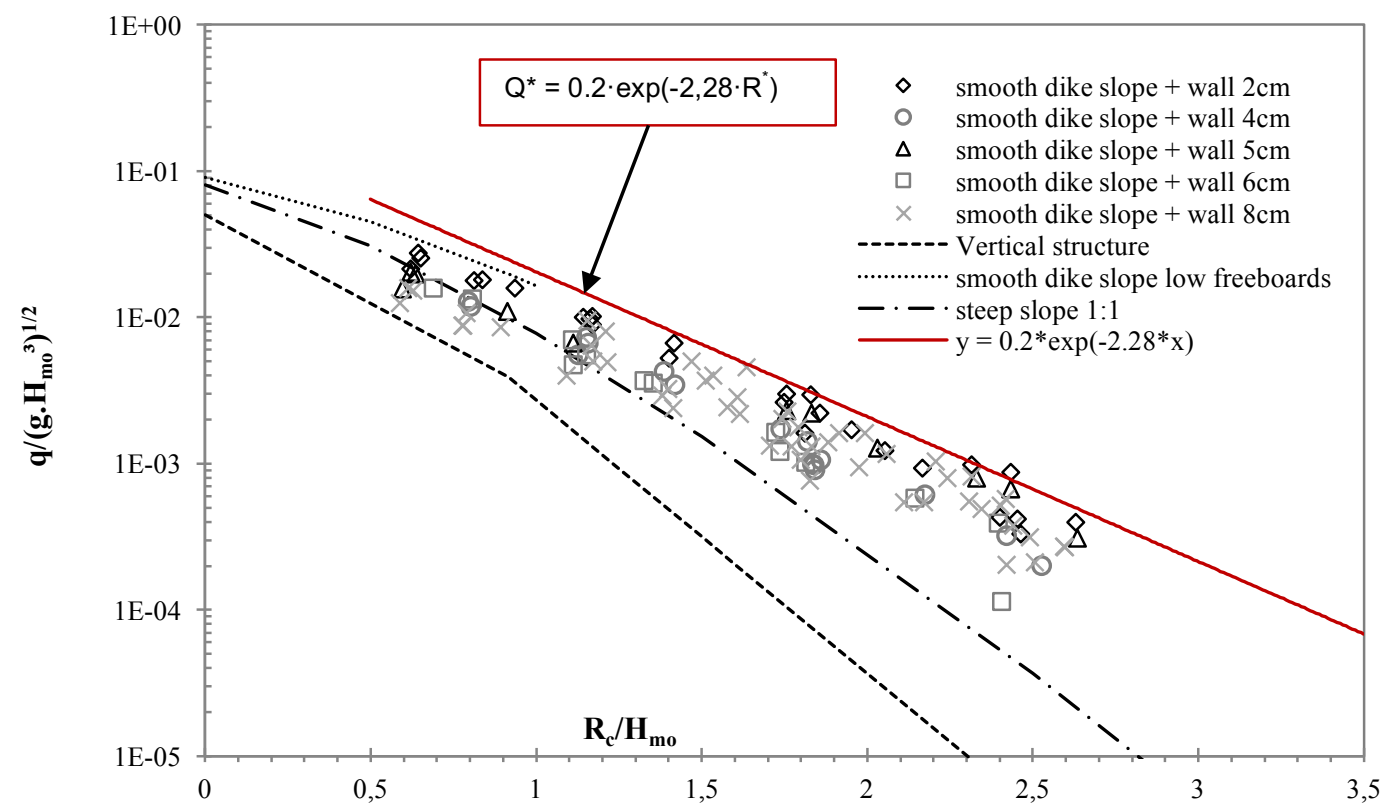

Figure 13. Measured data of the overtopping discharges over a dike slope with storm wall, non-breaking waves. Figure by Van Doorslaer et al. (2015), wall heights given in model scale values, scaled down to prototype with $\mathrm{N}_{\mathrm{L}}=20$.

Rewriting Eq. [9] leads to Eq. [10] with whom a reduction factor $\gamma_{\mathrm{v}}$ can be calculated for every single data point in Figure 13 to be shifted to the red reference line.

$$
\gamma_{v}=\frac{-2.28 \cdot \frac{R_{c}}{H_{m 0}}}{\ln \left(\frac{q}{0.2 \cdot \sqrt{g \cdot H_{m 0}^{3}}}\right)}
$$

The $\gamma_{\mathrm{v}}$-values for all these datapoints are now plotted in Figure 14 in terms of their dominating parameter, the dimensionless height of the wave wall.

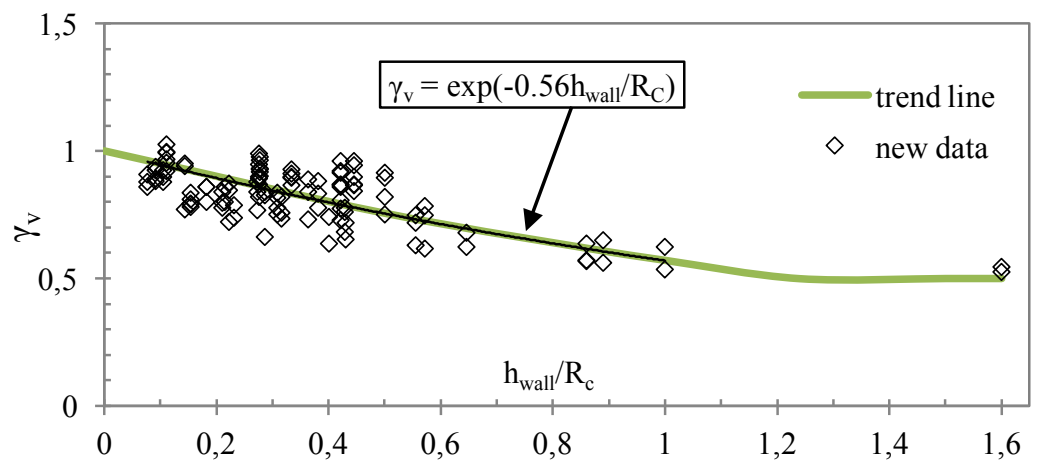

Figure 14. Calculated $\gamma_{v}$ as a function of $h_{\text {wall }} / R_{c}$. Figure by Van Doorslaer et al. (2015)

The reduction factor $\gamma_{\mathrm{v}}$ is defined in Eq. [11], as a best fitting curve through the data in Figure 14. 


$$
\begin{array}{ll}
\gamma_{v}=\exp \left(-0.56 \cdot \frac{h_{\text {wall }}}{R_{c}}\right) & \text { for } \frac{h_{\mathrm{wall}}}{\mathrm{R}_{c}}<1.24 \\
\gamma_{v}=0.5 & \text { for } \frac{h_{\mathrm{wall}}}{\mathrm{R}_{c}} \geq 1.24
\end{array}
$$

The introduction of Eq. [11] in Figure 13 leads to Figure 15 where the data points are much better predicted by the reference line according to eq. [9].

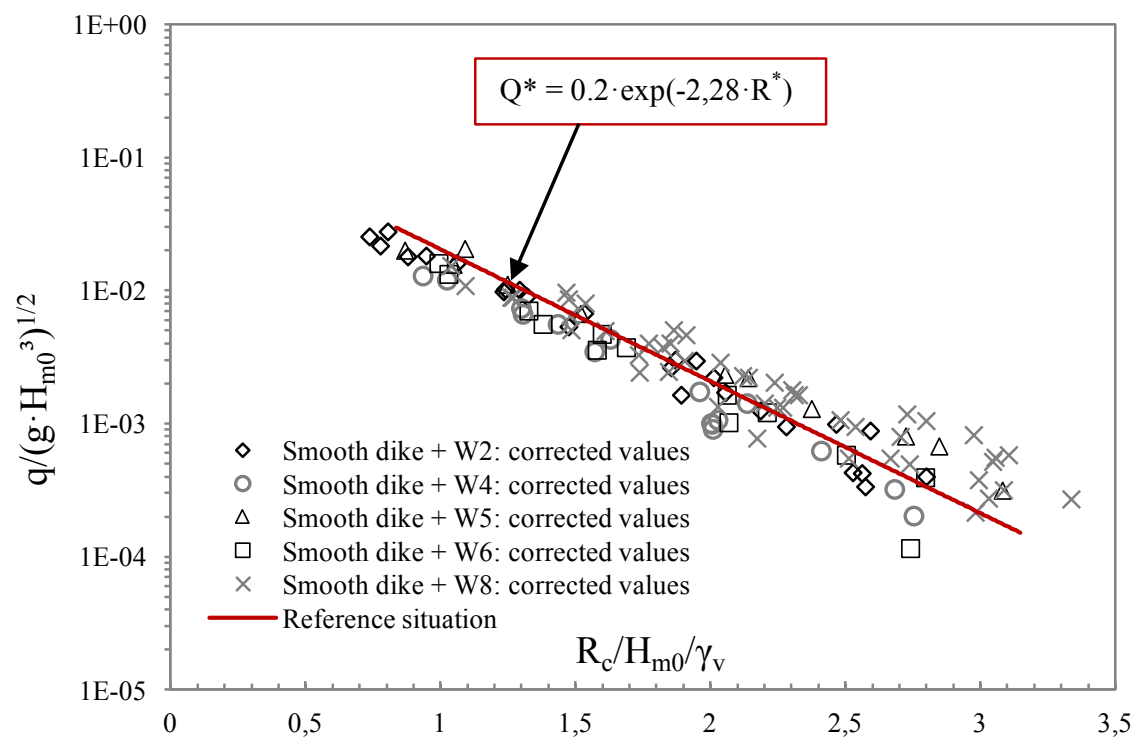

Figure 15. The data points from Figure 13 corrected by Eq. [11] gives a much better prediction of the data by the orange line Eq. [9]. Figure by Van Doorslaer et al. (2015)

\section{UGent dataset for breaking waves}

A similar analysis for the UGent data set of breaking waves is done as in the previous section for non-breaking waves. In contrast with Harlingen dataset but similar to UGent's non-breaking dataset, the actual slope $\alpha$ is used for calculating the breaker parameter, again for the same reason: a relatively small wave wall does not influence the breaker parameter analysis when using the actual slope instead of the average slope. A reference situation, a smooth dike slope without wave wall, was tested first. Results are presented in Figure 16 together with Eq. [1] from EurOtop (2007) and the 90\% confidence interval.

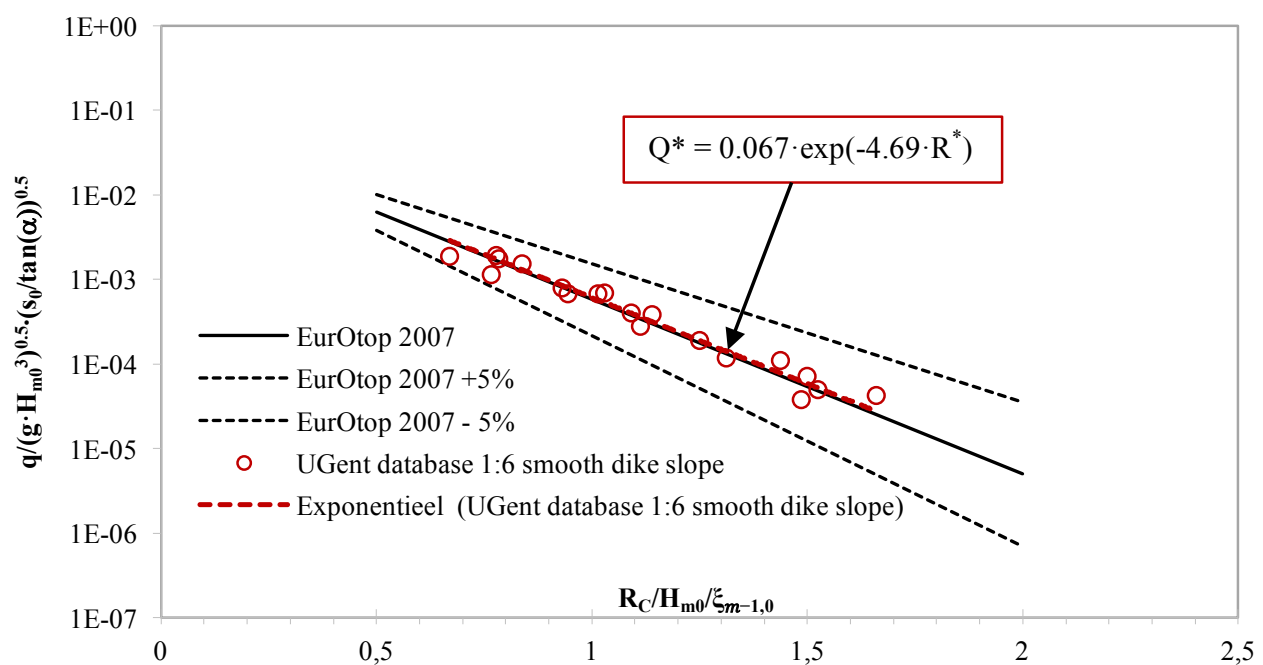

Figure 16. Measured data over a smooth dike slope 1:6, breaking waves. Wall heights given in model scale values, scaled down to prototype with $\mathrm{N}_{\mathrm{L}}=\mathbf{5 0}$. 
Even though the data are very close to the reference line, the coefficient 4.69 instead of 4.75 from Eq. [1] is used in analysis of $\gamma_{v}$, to have the best possible representation of the reduction factor.

When the 31 tests with wave wall are plotted in Figure 17, it can be seen that they are (nearly) all located a little below the red dashed reference line found in Figure 16, showing the (small) reductive effect from the wave wall on top of a gentle sloping dike. Three different wall heights have been tested, but due to the limited amount of reduction, no clear difference is found between them. The reduction factor $\gamma_{\mathrm{v}}$ has a constant value and is independent on the wall height.

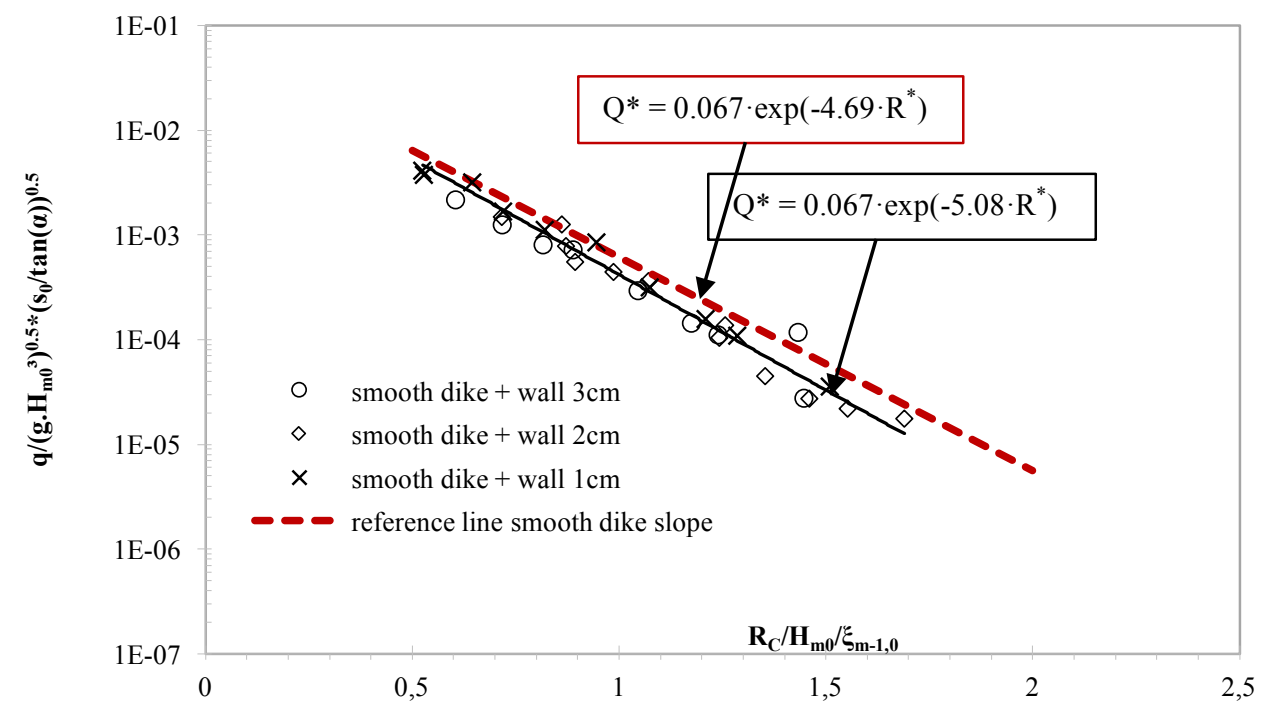

Figure 17. Measured data on a smooth dike slope 1:6 with wave wall, breaking waves.

The ratio of the exponential coefficients of the reference line (4.69) and the trendline through the data on the dike slope with wall (5.08) gives $\gamma_{\mathrm{v}}=0.92$, the reduction factor for breaking waves on a dike slope $(\tan (\alpha)=1: 6)$ with a wave wall. This reduction factor can be introduced in Eq. [1] or [3] for breaking waves.

\section{REDUCTION FACTOR FOR WAVE WALLS, A PROCEDURE BASED ON ALL AVAILABLE DATA}

The analysis in Chapter 5 has shown some differences between the different datasets:

- In the Harlingen dataset, the wall formed an important part of the geometry. In the analysis, the vertical wall was replaced by a 1:1 slope for calculating the average slope, which was used in the wave breaker parameter. This value determines if waves were breaking or not. In the analysis of the UGent datasets, the wall was located above the still water level and did not influence the breaker parameter much. Thus, the actual slope $\alpha$ was used to determine the wave breaker parameter and the selection between breaking and non-breaking waves.

- The Harlingen dataset gives a reduction factor for breaking waves only, being $\gamma_{\mathrm{v}}=0.65$. The UGent dataset shows a reduction factor both for non-breaking waves (Eq. [11]) and for breaking waves $\left(\gamma_{\mathrm{v}}=0.92\right.$, which is a much lower reduction compared to the Harlingen dataset).It is now investigated if one procedure works better than the other.

It's clear that the UGent data on a dike with storm wall are not predicted well by the Harlingen procedure. A small wall on top of the structure doesn't influence the average slope in such a way that waves are shifted from non-breaking to the breaking regime (see Figure 11). For the non-breaking waves, no reduction factor is available, which doesn't fit the UGent's non-breaking data. For the breaking waves, the reduction factor $\gamma_{\mathrm{v}}=0.65$ is too strong for what is found in UGent's breaking data.

The datasets from the UGent experiments (non-breaking and breaking) can mainly be generalized by the fact that the wall was a small part of the total construction. In the dataset with breaking waves, the wall always started above the SWL. In the dataset with the breaking waves, the wall also started above the SWL in almost all tests (115 of the 117 tests). Summarized, it can be said that the procedure for Harlingen doesn't work well for (UGent) tests with an emerged wall. 
The other way around, can the UGent procedure be used for the (Harlingen) data? When using the actual slope $\alpha$ instead of an equivalent slope $\alpha_{\mathrm{eq}}$, and keeping the distinction between breaking and nonbreaking waves unchanged (maintaining the minimum of both values) less points shift from the nonbreaking regime to the breaking regime. By introducing $\gamma_{\mathrm{v}}$ from Eq. [11] in the non-breaking graph, and $\gamma_{\mathrm{v}}=0.92$ in the breaking graph, Figure 18 and Figure 19 are found. Note that for the dataset with slope $1: 3$ and a $0.40 \mathrm{~m}$ wide promenade in front of the storm wall also the reduction factor for a promenade by Van Doorslaer et al. (2015) was taken into account.

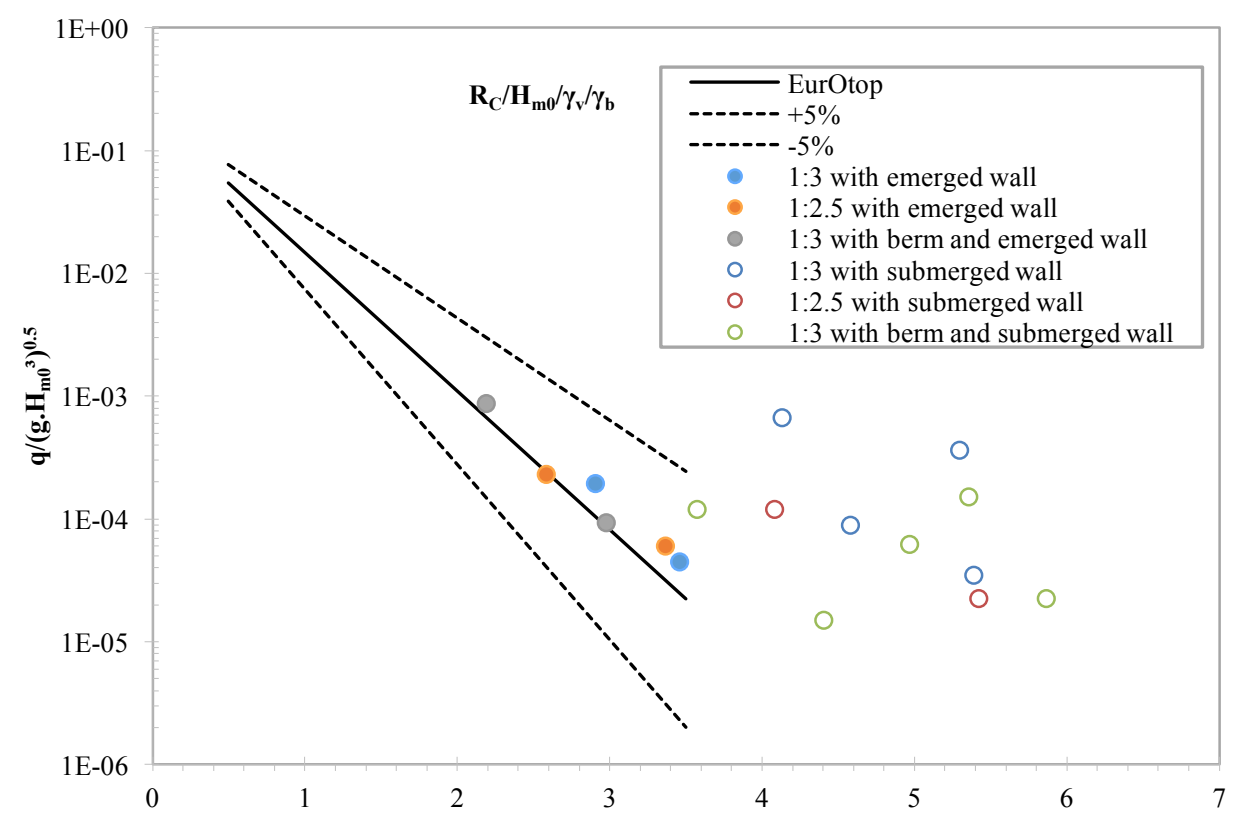

Figure 18. All non-breaking waves from the Harlingen dataset, using the actual slope $\alpha$ and the boundary between breaking and non-breaking based on their minimum value. Data points are corrected by $\gamma_{v}$ from Eq. [11] and where necessary also by $\gamma_{b}$ by Van Doorslaer et al. (2015).

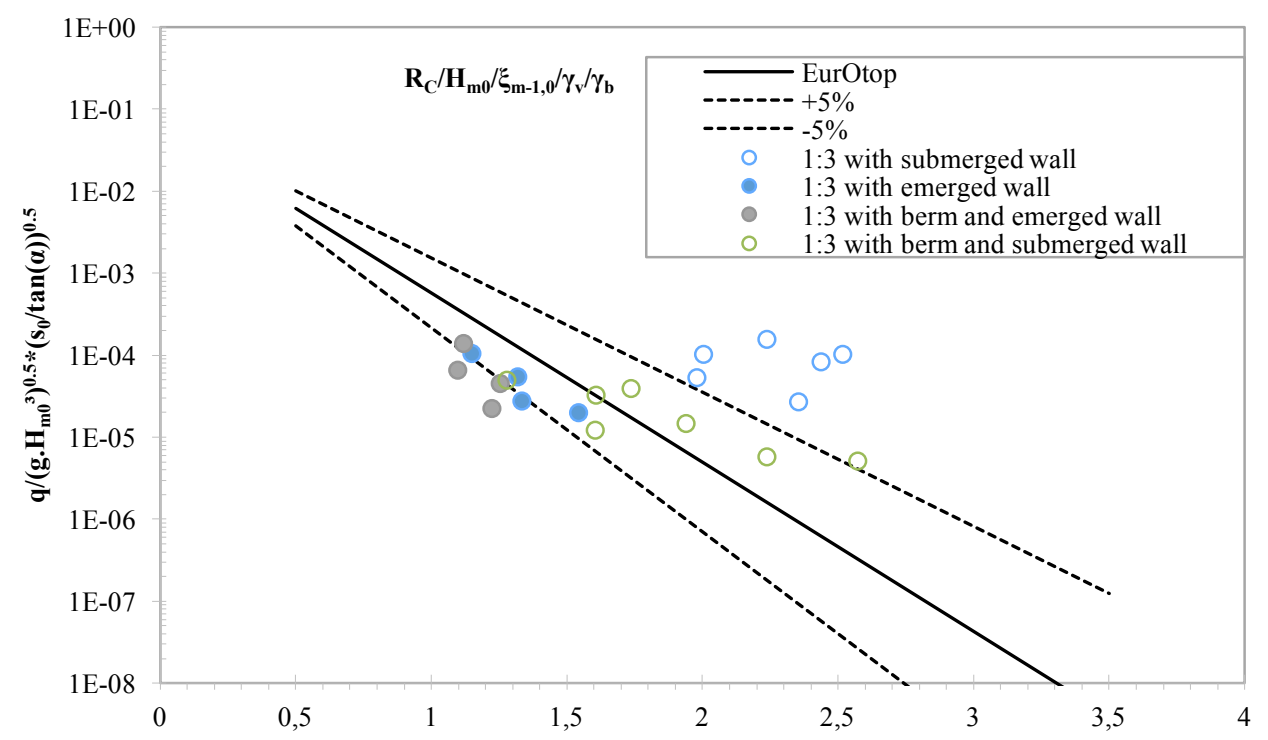

Figure 19. All breaking waves from the Harlingen dataset, using the actual slope $\alpha$ and the boundary between breaking and non-breaking based on their minimum value. Data points are corrected by $\gamma_{v}=0.92$ and where necessary also by $\gamma_{b}$ by Van Doorslaer et al. (2015).

The data in Figure 18 and Figure 19 have been split up between an emerged wall (SWL below foot of the wall) and a submerged wall (SWL above foot of the wall). It can be seen that the data for emerged wall (full data mark) are predicted fairly well by the black reference line, where the data for a 
submerged wall (open data mark) are mostly outside the $90 \%$ confidence interval and thus predicted poor by the black reference line.

Summarized, it can be concluded that the UGent procedure works well for the Harlingen tests with emerged wall, but not for the tests with submerged wall.

\section{SUMMARY AND PROCEDURE AS INCLUDED IN EUROTOP (2016)}

According to the second edition of EurOtop (2016), overtopping over sloping structures can be calculated by means of Eq. [3] and [5]:

$$
\begin{gathered}
\frac{q}{\sqrt{g \cdot H_{m 0}^{3}}}=\frac{0.023}{\sqrt{\operatorname{tan\alpha }}} \cdot \gamma_{b} \cdot \xi_{m-1,0} \cdot \exp \left[-\left(2.7 \cdot \frac{R_{C}}{H_{m 0}} \cdot \frac{1}{\xi_{m-1,0} \cdot \gamma_{b} \cdot \gamma_{f} \cdot \gamma_{\beta} \cdot \gamma_{v}}\right)^{1.3}\right] \\
\text { with a maximum of: } \frac{q}{\sqrt{g \cdot H_{m 0}^{3}}}=0.09 \cdot \exp \left[-\left(1.5 \cdot \frac{R_{C}}{H_{m 0}} \cdot \frac{1}{\gamma_{f^{\prime}} \cdot \gamma_{\beta} \cdot \gamma_{v}}\right)^{1.3}\right]
\end{gathered}
$$

In the beginning of this paper and Figure 5.16 from EurOtop (2016), it was shown that even though a reduction factor was distracted from a previous formula, it still is valid to be used in the newest form of the formula. This is because the reduction factor is a relative value that shows how much a certain geometry reduces the wave overtopping in comparison with a reference situation. If for the adapted geometry as well as for the reference situation both the former formula has been used, the derived reduction factor can later be used in the new formula to give information on the amount of reduction.

The reduction factor for wave walls $\gamma_{\mathrm{v}}$ was defined in 2 different references which did not match: EurOtop (2007), who based its information on the Harlingen dataset from 1994, worked with an average slope and stated a reduction factor was only required for breaking waves, versus Van Doorslaer et al. (2015) who only studied non-breaking waves used the actual slope and concluded the necessity of a reduction factor anyhow. New tests were carried out, similar to the tests in Van Doorslaer et al. (2015) but this time for breaking waves on a smooth mild sloping dike $(\tan (\alpha)=1: 6)$. This data confirmed the necessity of $\gamma_{\mathrm{v}}$ for breaking waves, but found the reduction factor to be much closer to 1 : not as much reducing the wave overtopping discharge as stated in EurOtop (2007).

The original data and analysis were reconsidered, and both theories seem to be complementary, each within its own parameter interval. The boundary for both is at $h_{w a l l} / R_{c}=1$. The EurOtop (2007) guidance remains valid for relatively large walls with their foot below $S W L, h_{\text {wall }} / R_{c}>1$, where the wall is part of the dike so that an average slope approach is proposed. The guidance by Van Doorslaer et al. (2015) for non-breaking waves and by the new research for breaking waves is valid for small walls on top of the dike slope with their foot above $S W L, h_{\text {wall }} / R_{c}<1$, where the slope is not influenced much so that the actual slope can be maintained.

\section{Wave wall with submerged foot $h_{\text {wall }} / \mathbf{R}_{c}>1$, guidance as in EurOtop (2007):}

By analyzing the Harlingen dataset, it was found that the wave wall has to be schematized as a 1:1 slope with the same value of freeboard $R_{c}$ to calculate the average slope. With this average slope, the wave breaker parameter is calculated to determine whether a wave is breaking or non-breaking, with the boundary set at $\gamma_{b} \xi_{0 p}=3$. Smaller values give breaking waves, larger values non-breaking waves. In the formula [3] for breaking waves, a reduction factor $\gamma_{\mathrm{v}}=0.65$ has to be included. In the formula [5] for non-breaking waves, no reduction factor is required $\left(\gamma_{\mathrm{v}}=1\right)$. This application is limited to slopes between $\cot (\alpha)=2.5$ and 3 , and the foot of the wall is between $-1.2 * \mathrm{H}_{\mathrm{m} 0}$ below SWL and the SWL.

\section{Wave wall with emerged foot $h_{\text {wall }} / R_{c}<1$, breaking waves.}

New model tests at Ghent University have been performed on a smooth dike with very gentle slope where breaking waves were measured. The overtopping over a small wave wall on top of the structure was compared to overtopping over a dike slope with similar crest height without wave wall. This lead to a reduction factor $\gamma_{\mathrm{v}} 0.92$, to be used in Eq. [3] together with the actual slope $\alpha$ in determining the breaker parameter. This is valid for a dike slope with $\cot (\alpha)=6$ and the foot of the wave wall is above $\mathrm{SWL} \mathrm{h}_{\text {wall }} / \mathrm{R}_{\mathrm{c}}<1$. 


\section{Wave wall with emerged foot $h_{\text {wall }} / \mathbf{R}_{c}<1$, non-breaking waves.}

The largest dataset was set-up at Ghent University for non-breaking waves and analyzed in Van Doorslaer et al. (2015), with use of the actual slope $\alpha$. Steeper slopes $(\tan (\alpha)=1: 2$ and 1:3) were tested and it was found that also for non-breaking waves a reduction factor has to be included in Eq. [5] to account for the use of a wave wall on top of the structure. Analysis has shown that this reduction factor $\gamma_{\mathrm{v}}$ is dependent on the height of the storm wall:

$$
\gamma_{v}=\exp \left(-0.56 \cdot \frac{h_{\text {wall }}}{R_{c}}\right)
$$

This is valid for a dike slope between $\cot (\alpha)=2$ and 3 and the foot of the wall is above SWL $\mathrm{h}_{\text {wall }} / \mathrm{R}_{\mathrm{c}}<1$.

Based on this work, EurOtop (2016) gives an updated advice for the influence of wave walls on sloping dikes in comparison with EurOtop (2007), and also included the influence of a promenade and a bullnose at the vertical wall.

\section{REFERENCES}

Den Heijer, F., 1998. Golfoverslag en krachten op vertical waterkeringsconstructies. Rapport H2014 (in Dutch)

EurOtop, 2007. Wave Overtopping of Sea Defences and Related Structures: Assessment Manual. Pullen, T., Allsop, N.W.H., Bruce, T., Kortenhaus, A., Schüttrumpf, H., van der Meer, J.W. www.overtopping-manual.com.

EurOtop, 2016. Manual on wave overtopping of sea defences and related structures. An overtopping manual largely based on European research, but for worldwide application. Van der Meer, J.W., Allsop, N.W.H., Bruce, T., De Rouck, J., Kortenhaus, A., Pullen, T., Schüttrumpf, H., Troch, P. and Zanuttigh, B., www.overtopping-manual.com.

Mertens, T., De Wolf, P., Verwaest, T., Trouw, K., De Nocker, L., Coudere, K., 2009. An integrated master plan for Flanders future coastal safety. ASCE. Proceedings of ICCE 2008. pp. 4017-4028

TAW, 2002. Technical report. Wave runup and wave overtopping at dikes. Technical Advisory Committee on Flood Defence, Delft.

Van der Meer, J.W., 1997. Golfoploop en golfoverslag bij dijken. Rapport H2458 (in Dutch)

Van der Meer, J.W. and Bruce, T., 2014. New physical insights and design formulas on wave overtopping at sloping and vertical structures. ASCE Journal of Waterway, Port, Coastal \& Ocean Engineering.

Van der Meer, J.W. and Janssen, J.P.F.M., 1994. Wave run-up and wave overtopping at dikes. ASCE. In: Wave forces on inclined and vertical wall structures, ed. N. Kobayashi and Z. Demirbilek, pp. 1-27. Also Delft Hydraulics Publication nuMBer 485

Van Doorslaer, K., De Rouck, J., Audenaert, S., Duquet, V., 2015. Crest modifications to reduce wave overtopping of non-breaking waves over a smooth dike slope. Elsevier, Journal of Coastal Engineering 101, pp. 69-88.

Victor, L., 2012. Optimization of the Hydrodynamic Performance of Overtopping Wave Energy Converters: Experimental Study of Optimal Geometry and Probability Distribution of Overtopping Volumes. PhD Manuscript, Ghent University. 